\title{
A new diagnostic real-time PCR method for huanglongbing detection in citrus root tissue
}

\author{
Jong-Won Park ${ }^{1}$ (D) Eliezer S. Louzada ${ }^{1} \cdot$ W. Evan Braswell ${ }^{2}$ Philip A. Stansly ${ }^{3} \cdot J^{\prime}$ ohn V. da Graça ${ }^{1} \cdot$ Greg McCollum $^{4}$. \\ John E. Rascoe ${ }^{5} \cdot$ Madhurababu Kunta $^{1}$
}

Received: 31 December 2017 / Accepted: 23 April 2018 / Published online: 13 June 2018

(c) The Author(s) 2018, corrected publication August 2018

\begin{abstract}
Citrus fibrous root tissue was evaluated as an alternative source material for huanglongbing (HLB) diagnosis by real-time PCR using primer-probe set TXCChlb, developed in the present study based on 16S rDNA of "Candidatus Liberibacter asiaticus" (CLas). Real-time PCR data obtained with DNA samples prepared from leaf and fibrous root tissue collected from mature ( $>10$ years old) and young (4-5 years old) citrus trees growing in Texas and Florida confirmed that root HLB test is more sensitive than the leaf HLB test in terms of the detection rate of HLB positive trees. In addition, the current study confirmed that HLB can be diagnosed at the pre-symptomatic stage using the root HLB test to facilitate efficient removal of HLB-positive, asymptomatic trees that could serve as a source for HLB. The new HLB diagnostic method using root tissue described in the current study can assist in deploying a more efficient disease management strategy to deter HLB spread, especially at the pre-symptomatic stage.
\end{abstract}

Keywords HLB · "Candidatus Liberibacter asiaticus" · Real-time PCR · Root · CLas 16S rDNA · Citrus greening

\section{Introduction}

Huanglongbing (HLB), also known as citrus greening, is the most serious disease affecting citrus production in Asia, Africa, Americas and the Arabian Peninsula (Bové 2006; Gottwald 2010). HLB has been associated with three related but distinct Gram-negative phloem-inhabiting

Electronic supplementary material The online version of this article (https://doi.org/10.1007/s10327-018-0793-4) contains supplementary material, which is available to authorized users.

Madhurababu Kunta

madhura.kunta@tamuk.edu

1 Texas A \& M University-Kingsville Citrus Center, 312 N. International Blvd, Weslaco, TX 78599, USA

2 Mission Laboratory, USDA APHIS PPQ CPHST, Edinburg, TX 78539, USA

3 Southwest Florida Research and Education Center, University of Florida-IFAS, Immokalee, FL 334142, USA

4 USDA-ARS Horticultural Research Laboratory, Fort Pierce, FL 34945, USA

5 Beltsville Laboratory, USDA APHIS PPQ CPHST, Beltsville, MD 20705, USA
$\alpha$-Proteobacteria "Candidatus Liberibacter asiaticus" (CLas) (Jagoueix et al. 1994), "Ca. L. africanus" (CLaf) (Planet et al. 1995), and "Ca. L. americanus" (CLam) (Teixeira et al. 2005). Among these three " $\mathrm{Ca}$. Liberibacter" species, CLas is the most widespread and poses the greatest threat to the citrus industry around the world, while CLaf and CLam are geographically isolated, mostly in Africa and South America, respectively (da Graça and Korsten 2004; Gottwald 2010; Teixeira et al. 2005). In the United States, HLB caused by CLas was first found in Florida in 2005 (Gottwald 2010), and subsequently reported from several states including Georgia, Louisiana, South Carolina, Texas, and California (Wang and Trivedi 2013). Because the pathogen is spread by psyllids (Capoor et al. 1967; McClean and Oberholzer 1965; Wang and Trivedi 2013) and through propagation of infected material, a three-pronged disease management approach that includes inoculum reduction by the removal of trees with HLB disease, control of psyllid vector populations, and production of healthy trees for planting is recommended (da Graça and Korsten 2004).

Pre-symptomatic detection of CLas is critical for the success of inoculum reduction programs because the pathogen can be spread by the vector from newly infected leaves within 15 days after CLas introduction by psyllids and may be a major 
mode of HLB spread in an orchard (Lee et al. 2015). However, detection of CLas infection is difficult due to the fastidious nature of the bacterium, the uneven distribution of CLas in the citrus tree canopy and the prolonged incubation periods before symptoms are visible - from a few months to 1 or more years after natural inoculation (Bové 2006; Gottwald 2010; Shen et al. 2013). Moreover, in combination, these characteristics can further delay detection of the disease. For example, efficient surveys are hampered by the patchy distribution of the symptoms used to identify trees with sufficient probability of CLas detection. In this situation, delayed symptom development hinders detection (Gottwald et al. 2008; Lee et al. 2015; Li et al. 2006).

Although CLas is introduced into a healthy tree via psyllid feeding on leaves, Johnson et al. (2014) found that root tissues exhibited damage before symptoms became visible on leaves. Moreover, recent studies have shown that CLas distribution is much more uniform in the roots than in the canopy (Louzada et al. 2016). Together, these findings suggest that roots represent a better sampling pool for CLas detection (Kunta et al. 2014a; Louzada et al. 2016).

The most widely used real-time PCR primer-probe set, HLBaspr targeting the CLas 16S rDNA region, however, gives unreliable results for root samples due to nonspecific amplification (Kunta et al. 2014b; Louzada et al. 2016). Such nonspecific amplicons are not produced by other real-time PCR primer-probe sets available for CLas detection in roots such as CQULA (CQULA04F/CQULA04R and TaqMan probe CQULAP10) (Wang et al. 2006), LJ900fpr (Morgan et al. 2012), and RNR (Zheng et al. 2016). The genomic regions targeted by these primer sets are $\mathrm{rplJ} / \mathrm{rpl} \mathrm{L}$ ribosomal protein gene for CQULA (Wang et al. 2006), hyvI/hyvII multiple tandem repeats for LJ900fpr (Morgan et al. 2012), and $n r d B$ gene for RNR (Zheng et al. 2016), which are different from that of the HLBaspr primer-probe set ( $\mathrm{Li}$ et al. 2006).

Bacterial 16S rDNA has been extensively investigated as a tool for the identification and phylogenetic study of prokaryotes due to its evolutionarily conserved nature and the presence of a range of variable regions (Yarza et al. 2010). In the current study, we therefore investigated the nucleotide sequence variation present in $16 \mathrm{~S}$ rDNAs between CLas and other " $\mathrm{Ca}$. Liberibacter" spp. that are associated with the diseases on citrus and potato to develop a new set of real-time PCR primers for the detection of HLB-causing bacteria from citrus root tissue. The current study developed a new set of primers and probe based on the nucleotide sequence of CLas 16S rDNA and investigated its usefulness for HLB detection in root tissue of pre-symptomatic citrus trees.

\section{Materials and methods}

\section{Multiple nucleotide sequence analysis}

The 16S rDNA sequences of CLam (NC022793), Ca. L. solanacearum (NC014774), CLaf (NZ_CP004021), CLas (NC012985, NZ_CP010804, NC020549, NZ_AP014595), which had complete genomic sequences available in the NCBI GenBank (https://www.ncbi.nlm.nih.gov) when the current study was initiated, were used for multiple nucleotide sequence alignment using Clustal Omega (https://www. ebi.ac.uk/Tools/msa/clustalo). A new set of primers (TXCChlb-f; 5'-CTTTTCGGAGACCTTTACACA-3' and TXCChlb-r; 5'-CTTGATGGCAACTAGAGGCA-3') and a probe (TXCChlb-p; 5'-TGCGCTCGTTGCGGGACTTA-3') were designed from the region conserved among CLas strains, but not with other " $\mathrm{Ca}$. Liberibacter" species, using Primer3 (Koressaar and Remm 2007) followed by visual inspection (Fig. 1). The amplification efficiency of the newly designed primer-probe set, TXCChlb, was examined by a procedure described below in real-time PCR and conventional PCR (cPCR).

\section{Fibrous root tissue sampling and DNA extraction}

Fibrous roots were collected from 2 to 5 inches below the soil surface at four different quadrants within 2 feet from the tree trunk, which were then pooled and air-dried in a paper bag at room temperature $\left(\sim 25^{\circ} \mathrm{C}\right)$ for about $24 \mathrm{~h}$ to facilitate easy removal of excessive soil by tapping with fingers. Root DNA was extracted from $\sim 150 \mathrm{mg}$ of finely sliced root tissue using a DNeasy PowerPlant Pro HTP 96 kit (Qiagen, Hilden, Germany) and the manufacturer's instruction with some modification (Supplementary Document 1). PCR inhibitors from the root DNA fraction were removed by using a PCR inhibitor removal kit (Zymo Research, Irvine, CA, USA) followed by $1: 1$ dilution with sterilized $\mathrm{dH}_{2} \mathrm{O}$ to minimize potential effects of any remaining PCR inhibitors (Supplementary Document 1 ). Two and $4 \mu \mathrm{l}$ of root DNA extracts were used for real-time PCR and cPCR, respectively, following the PCR parameters described below.

\section{Real-time PCR and conventional PCR}

The amplification efficiency of the newly developed primerprobe set (TXCChlb) was examined using the OI1-OI2c amplicon (Jagoueix et al. 1996) amplified from CLas 16S rDNA and cloned into pCR2.1 TOPO vector (Invitrogen, Carlsbad, CA, USA). A series of 1:10 dilutions of the plasmid containing the OI1-OI2c amplicon was prepared with sterilized $\mathrm{dH}_{2} \mathrm{O}$ for use as a template for the real-time PCR 
from a commercial orchard in Donna, Texas in order to examine the usefulness of TXCChlb for HLB detection at pre-symptomatic stage. Before sampling for this study, these trees had not been tested for CLas infection. Among these trees, only two trees (Tree ID: a1 and a2) had phenotypes that could be confused for HLB symptoms, whether these phenotypes were due to nutrient deficiency or CLas infection was unknown at the time of sampling. For comparison, we sampled two neighboring mature ( $>10$ years old) 'Rio Red' grapefruit trees that had previously tested positive for CLas in real-time PCR using HLBaspr and leaf DNA.

\section{Results}

\section{Multiple sequence analysis of 16S rDNA of various Candidatus Liberibacter species}

Multiple sequence alignment revealed a few regions that are conserved among CLas strains, but not with other " $\mathrm{Ca}$. Liberibacter" species (Fig. 1). These regions were analyzed to design real-time PCR primers and probe using Primer3 (Koressaar and Remm 2007) and by visual inspection, which led to the development of new real-time PCR primers based on CLas 16S rDNA (Fig. 1). To examine any potential crossreactivity of the newly designed primer set, TXCChlb, with 16S rDNAs of other soil bacteria, we did a BLASTn search of the prokaryotic ribosomal RNA database after excluding the CLas 16S rDNA sequence (NCBI TaxID 34,102) and found that TXCChlb-f has $\leq 66 \%$ sequence coverage with $100 \%$ identity to the sequences on the prokaryotic $16 \mathrm{~S}$ rDNA database, while TXCChlb-r has a maximum of $90 \%$ sequence coverage with $100 \%$ identity to the prokaryotic 16S rDNA database (data not shown). The predicted amplification efficiency of TXCChlb was $\sim 97 \%$ (Fig. 2).

\section{Specificity of TXCChlb}

For examining the specificity of TXCChlb, DNA fractions that contain 16S rDNA of three " $\mathrm{Ca}$. Liberibacter" species, CLas, CLam and CLaf, were obtained from the USDA APHIS Lab at Beltsville, MD and used for real-time PCR with TXCChlb following the PCR parameters described in Materials and Methods. The result (Fig. 3) showed that TXCChlb detected all three HLB causing " $\mathrm{Ca}$. Liberibacter" species. The efficiency of TXCChlb for the detection of each of all three HLB causing bacteria, CLas, CLam and CLaf was tested using real-time PCR with a series of diluted template DNAs which were prepared from the DNA templates used for the reaction in Fig. 3. For comparison, real-time PCR primer sets targeting 16S rDNA of CLas (HLBaspr), CLam (HLBampr) and CLaf (HLBafpr) (Li et al. 2006) were included because their nonspecific amplification renders them unsuitable for HLB detection in root tissue (data not shown). The test results (Table 1) showed that the efficiency of TXCChlb for CLas detection is comparable to that of

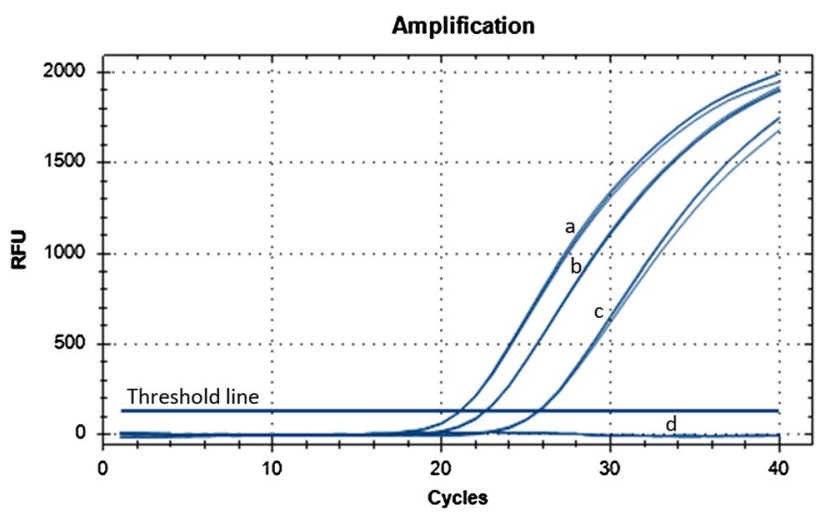

Fig. 3 TXCChlb specificity test by real-time PCR using DNA fractions that contained $16 \mathrm{~S}$ rDNA fragment of Candidatus Liberibacter asiaticus (CLas), Ca. L. americanus (CLam) and $\mathrm{Ca}$. L. africanus (CLaf). a CLam $(\mathrm{Ct}=21.13)$, b CLas $(\mathrm{Ct}=22.63)$, c CLaf $(\mathrm{Ct}=25.73), \mathbf{d}$ negative control. Threshold is indicated in the figure
Fig. 2 Amplification efficiency test of TXCChlb using OI1OI2c amplicon cloned into pCR2.1 TOPO vector. The gene copy number and threshold cycle $(\mathrm{Ct})$ value are shown in the table on the right

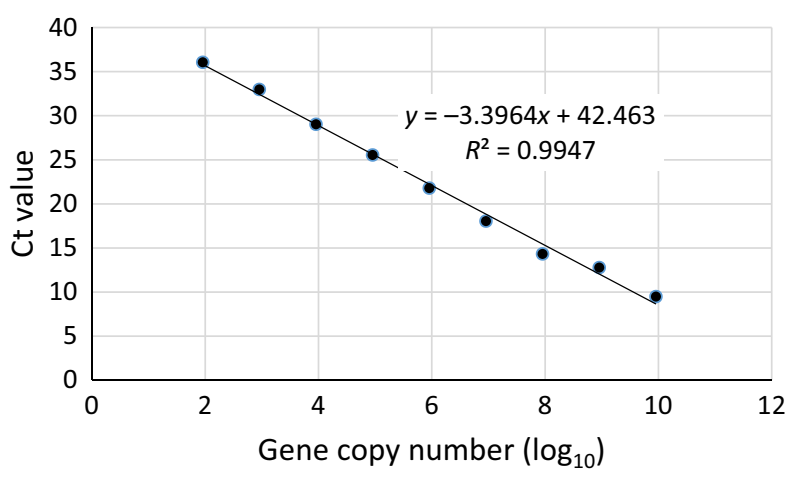

\begin{tabular}{|l|l|}
\hline $\begin{array}{l}\text { Copy } \\
\text { number } \\
\left(\log _{10}\right)\end{array}$ & Ct value \\
\hline 10 & 9.49 \\
\hline 9 & 12.78 \\
\hline 8 & 14.33 \\
\hline 7 & 18.04 \\
\hline 6 & 21.79 \\
\hline 5 & 25.54 \\
\hline 4 & 29.02 \\
\hline 3 & 32.98 \\
\hline 2 & 36.06 \\
\hline
\end{tabular}


Table 1 Detection efficiency of TXCChlb and other real-time PCR primer-probe sets targeting $16 \mathrm{~S}$ rDNAs of Candidatus Liberibacter asiaticus (CLas), Ca. L. americanus (CLam) and Ca. L. africanus (CLaf)

\begin{tabular}{|c|c|c|c|c|c|c|}
\hline \multicolumn{7}{|l|}{ Template DNA } \\
\hline \multirow[t]{3}{*}{ Dilution factor ${ }^{a}$} & \multicolumn{2}{|l|}{ CLas } & \multicolumn{2}{|l|}{ CLam } & \multicolumn{2}{|l|}{ CLaf } \\
\hline & HLBaspr $^{\mathrm{b}}$ & TXCChlb & HLBampr $^{\mathrm{b}}$ & TXCChlb & HLBafpr $^{\text {b }}$ & TXCChlb \\
\hline & $\mathrm{Ct}^{\mathrm{c}}$ & $\mathrm{Ct}$ & $\mathrm{Ct}$ & $\mathrm{Ct}$ & $\mathrm{Ct}$ & $\mathrm{Ct}$ \\
\hline $1 / 10$ & 26.05 & 26.17 & 23.63 & 24.53 & 27.93 & 36.83 \\
\hline $1 / 100$ & 29.21 & 29.34 & 26.56 & 27.40 & 31.34 & - \\
\hline $1 / 1000$ & 32.06 & 32.13 & 29.49 & 30.45 & 34.59 & - \\
\hline $1 / 10,000$ & 35.98 & 36.60 & 32.66 & 33.59 & 38.41 & - \\
\hline $1 / 100,000$ & 38.51 & 38.18 & 35.75 & 36.97 & - & - \\
\hline $1 / 1,000,000$ & - & - & 38.27 & - & - & - \\
\hline
\end{tabular}

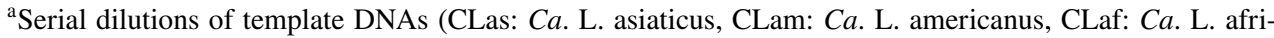
canus) from those tested in Fig. 3

${ }^{\mathrm{b}}$ HLBasrp, HLBampr, HLBafpr: real-time PCR primer-probe sets for CLas, CLam and CLaf detection

${ }^{\mathrm{c}}$ Threshold cycle $(\mathrm{Ct})$ : average $\mathrm{Ct}$ value of triplicates

- nondetectable level
HLBaspr and that TXCChlb can detect CLam although it is slightly less efficient than HLBampr due to the nucleotide mismatch between TXCChlb and its target region in CLam 16S rDNA (Fig. 1). On the other hand, TXCChlb is not suitable for CLaf detection because it can only detect CLaf when the titer is high (Table 1). In the United States, HLB is caused by CLas; thus, all HLB-positive or -symptomatic samples tested in the current study are HLB-positive samples caused by CLas. In addition, because Table 1 indicated that HLB detection sensitivity of TXCChlb is comparable to that of HLBaspr, we adopted the same USDA APHIS guideline suggested for HLBaspr to consider samples with threshold cycle $(\mathrm{Ct})$ less than 37 as HLB positive.

\section{Efficacy of TXCChlb for HLB diagnosis using citrus fibrous root tissue}

The efficacy of TXCChlb for HLB diagnosis was examined on the 76 citrus trees (see Materials and Methods) that had tested positive by real-time PCR using leaf DNA, together with HLBaspr (Li et al. 2006) and CQULA (Wang et al. 2006) for comparison. The HLB detection rate by realtime PCR with HLBaspr was $\sim 88 \%$ for sweet orange and $100 \%$ for grapefruit leaves (Table 2). In comparison, the real-time PCR with TXCChlb using leaf DNA extracts revealed $\sim 83$ and $100 \%$ detection rates in sweet orange and grapefruit, respectively, while root samples tested with TXCChlb showed $100 \%$ positive detection in both sweet orange and grapefruit (Table 2). On the other hand, the CQULA system applied to leaf DNA extracts resulted in $\sim 76$ and $\sim 97 \%$ detection in sweet orange and grapefruit, respectively, while root samples tested with CQULA showed $\sim 98 \%$ detection in sweet orange and $\sim 94 \%$ in
Table 2 HLB detection by three sets of real-time PCR primers and probe using leaf and root tissue samples collected from mature citrus trees previously determined to be Candidatus Liberibacter asiaticus (CLas)-positive. Percentage accuracy (i.e., detections from known infected trees) is in parentheses

\begin{tabular}{|c|c|c|c|c|}
\hline \multirow{3}{*}{$\begin{array}{l}\text { Primer-probe } \\
\text { set }\end{array}$} & \multicolumn{4}{|c|}{ Number of CLas positives (\% of total samples) } \\
\hline & \multicolumn{2}{|c|}{ Sweet orange $(N=41)$} & \multicolumn{2}{|c|}{ Grapefruit $(N=35)$} \\
\hline & Leaf & Root & Leaf & Root \\
\hline HLBaspr & $36^{\mathrm{a}}(87.8 \%)$ & nt & $35(100 \%)$ & nt \\
\hline CQULA & $31^{\mathrm{b}}(75.6 \%)$ & $40^{\mathrm{d}}(97.5 \%)$ & $34^{\mathrm{e}}(97.1 \%)$ & $33^{\mathrm{e}}(94.3 \%)$ \\
\hline TXCChlb & $34^{\mathrm{c}}(82.9 \%)$ & $41(100 \%)$ & $35(100 \%)$ & $35(100 \%)$ \\
\hline
\end{tabular}

CLas positives: $\mathrm{Ct}$ value $<37$ (based on USDA APHIS guideline for HLB diagnosis)

$n t$ not tested due to non-specific amplification with root samples

${ }^{\mathrm{a}} \mathrm{Ct}$ value of five CLas negatives $=37 \leq \mathrm{Ct}<38.5$

${ }^{\mathrm{b}} \mathrm{Ct}$ value of ten $\mathrm{CLas}$ negatives $=38.87<\mathrm{Ct}<40$

${ }^{\mathrm{c}} \mathrm{Ct}$ value of seven CLas negatives $=37.4<\mathrm{Ct}<40$

${ }^{\mathrm{d}} \mathrm{Ct}$ value of one CLas negative $=37.99$

${ }^{\mathrm{e}} \mathrm{Ct}$ value of CLas negatives $=37.1<\mathrm{Ct}<40$

grapefruit (Table 2). None of these three primer sets gave $100 \%$ detection of CLas using leaf DNA from the infected sweet orange trees (Table 2), perhaps due to erroneous leaf tissue sampling as a result of uneven distribution of aerial HLB symptoms and/or due to the similarity of HLB symptoms with various nutrient deficiencies. This data from HLB-positive mature trees suggested that (1) the detection rate for Liberibacter in leaves using TXCChlb is comparable to that with HLBaspr, (2) both HLBaspr and TXCChlb are more sensitive than CQULA, and (3) detection from root tissue using TXCChlb is more consistent than from leaves tested with HLBaspr. 


\section{Evaluation of HLB detection at pre-symptomatic stage using fibrous root tissue}

The potential of TXCChlb for asymptomatic HLB diagnosis by real-time PCR was evaluated using tissue samples collected from 21 young (4-5 years old) grapefruit trees and two HLB-positive mature grapefruit trees (see Materials and Methods). Of 21 young trees, two trees (a1 and a2) were positive for CLas in leaf samples with all three primer-probe sets (HLBaspr, CQULA and TXCChlb), while four trees (a1, a2, a7 and a9) tested positive for root samples using CQULA and TXCChlb (Table 3). The two neighboring mature trees were positive for CLas with all primer-probe sets using leaf tissue (Table 3). Root tissue samples from these mature trees produced positive results for CLas using TXCChlb in both trees, while only one root sample tested positive by CQULA (Table 3), suggesting that TXCChlb is likely more sensitive than CQULA.

The real-time PCR data obtained with TXCChlb for those six CLas-positive root samples (Table 3) were then

Table 3 Candidatus Liberibacter asiaticus (CLas) detection using different primer-probe sets and DNA from leaves and roots from young citrus trees with minor or no HLB-like symptoms and from known CLas-positive mature trees

\begin{tabular}{llllll}
\hline Primer-probe set & \multicolumn{2}{l}{ Number of CLas positives } \\
\cline { 2 - 3 } & Young tree $(N=21)$ & & \multicolumn{2}{l}{ CLas $(+)$ mature } \\
& tree $(N=2)$ & \\
\cline { 2 - 3 } \cline { 5 - 6 } & Leaf & Root & & Leaf & Root \\
\hline HLBaspr & $2^{\mathrm{a}}$ & $\mathrm{nt}$ & & $2^{\mathrm{c}, \mathrm{d}}$ & $\mathrm{nt}$ \\
CQULA & $2^{\mathrm{a}}$ & $4^{\mathrm{a}, \mathrm{b}}$ & & $2^{\mathrm{c}, \mathrm{d}}$ & $1^{\mathrm{c}}$ \\
TXCChlb & $2^{\mathrm{a}}$ & $4^{\mathrm{a}, \mathrm{b}}$ & & $2^{\mathrm{c}, \mathrm{d}}$ & $2^{\mathrm{c}, \mathrm{d}}$ \\
\hline
\end{tabular}

CLas positives: $\mathrm{Ct}$ value $<37$ (based on USDA APHIS guideline for HLB diagnosis)

$n t$ not tested due to nonspecific amplification with root samples

Tree IDs: a1 and a2

${ }^{b}$ Tree IDs: a7 and a9

${ }^{\mathrm{c}}$ Tree ID: b10

${ }^{\mathrm{d}}$ Tree ID: b11 confirmed using cPCR and cPCR primer sets OI1/OI2c (Jagoueix et al. 1996) and LSS/Las606 (Fujikawa and Iwanami 2012), which target CLas 16S rDNA. cPCR data showed that primer set OI1/OI2c produces non-target amplicons along with target amplicon and failed to confirm the real-time PCR data by agarose gel electrophoresis (Fig. 4a). Thus, OI1/ OI2c is not suitable for root cPCR, and these results agree with our previous reports (Kunta et al. 2014b; Louzada et al. 2016). On the other hand, primer set LSS/Las606 produced a single amplicon of $\sim 500 \mathrm{bp}$ in all six CLas positive root samples (Fig. 4b). The sequencing results showed that the nucleotide sequence of LSS-Las606 amplicons (GenBank ID: KY926796, KY926797) obtained from root samples completely matches the 16S rDNAs of CLas strains (e.g. CP010804, AP014595, CP004005 and CP001677). These data confirmed that those root samples that tested positive for CLas with TXCChlb are true positives and that HLB can be detected at a pre-symptomatic stage by using fibrous root tissue for the HLB test. In addition, the data in Table 3 showed that any potential cross-reactivity of TXCChlb to 16S rDNAs of other soil bacteria is negligible and that the root DNA extract prepared by the protocol described in Supplementary Document 1 is suitable for HLB detection by real-time PCR.

\section{Robustness of root HLB test compared to leaf HLB test}

To confirm the robustness of TXCChlb in the face of geographic, edaphic, and rootstock variation, TXCChlb was evaluated with leaf and root tissue samples collected in April 2016 from 99 sweet orange trees (4-5 years old) that were grown in Florida. The HLB diagnostic real-time PCR was conducted with HLBaspr for leaf and TXCChlb for root DNA extracts. Of 99 sweet orange trees, 17 trees tested positive for CLas with root samples, while only four trees were positive with leaf samples (Fig. 5a). Among these CLaspositive trees, two trees tested positive with both leaf and root tissue (Fig. 5a). cPCR conducted with LSS/Las606 (Fujikawa and Iwanami 2012) followed by agarose gel electrophoresis confirmed the presence of CLas 16S rDNA in 15
Fig. 4 Agarose gel electrophoresis of conventional PCR amplicons obtained from HLB-positive root DNA. a OI1/ OI2c amplicon. b LSS/Las606 amplicon. Lane M, DNA size markers. The tree ID is indicated at the top. The arrow and asterisk (*) in a indicate the OI1-OI2c amplicon and nonspecific amplicon, respectively

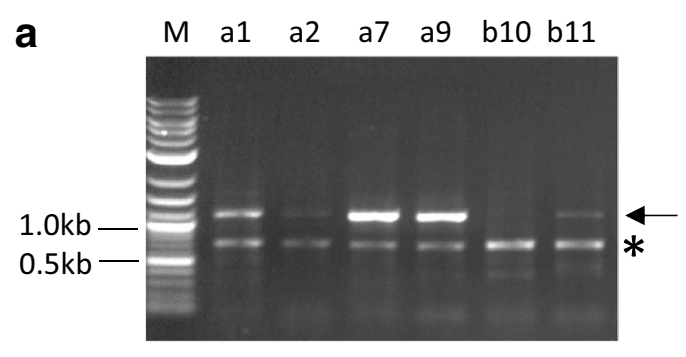

Ol1/OI2c

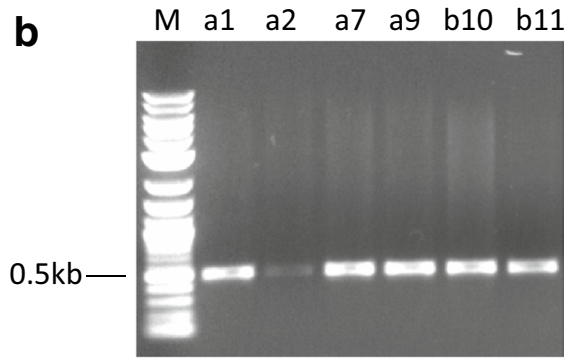

LSS/Las606 


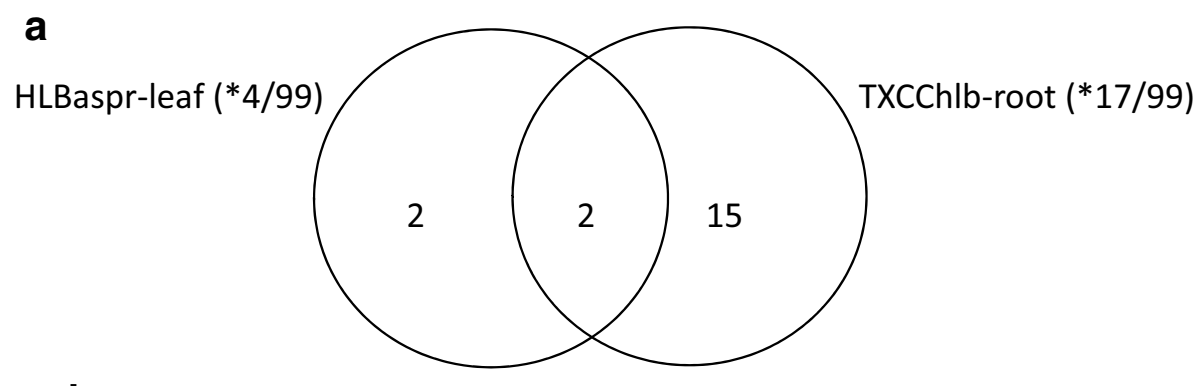

b

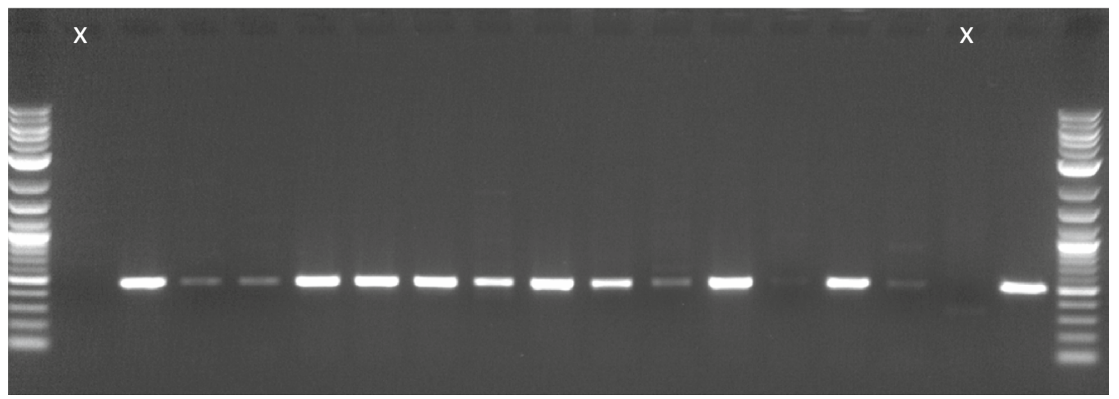

Fig. 5 Comparison of Candidatus Liberibacter asiaticus (CLas) detection results obtained with Florida leaf and root tissue samples using HLBaspr and TXCChlb (a) and agarose gel electrophoresis of conventional PCR amplicons of 17 CLas positives obtained with TXCChlb (b). Leaf and root samples were collected from each of 99 sweet orange trees grown in Florida in April 2016. The primer-probe

of 17 CLas positive root samples (Fig. 5b). The sequencing results showed that the nucleotide sequence of 501 bp LSSLas606 amplicons (GenBank ID: KY926798) obtained from these 15 CLas-positive root samples was a $100 \%$ match to the CLas 16S rDNA. The Ct values of the two samples for which cPCR failed were 36.27 and 36.21, respectively, suggesting that $\mathrm{Ct}$ value of $\sim 36$ obtained with TXCChlb may be the cPCR detection limit for CLas 16S rDNA (Fig. 5b).

\section{Discussion}

HLB, one of the oldest known citrus diseases, has caused unprecedented economic losses worldwide (Bové 2006). Since the first report of HLB in Florida in 2005 (Halbert 2005; Bové 2006; Gottwald 2010), the Florida citrus industry has suffered almost $67.4 \%$ yield decrease in orange production between 2007/2008 and 2015/2016 seasons (Monzo and Stansly 2017), and in 2014, the net capital loss (producer plus consumer losses) in Florida due to HLB was estimated at $\sim \$ 1$ billion per year (Farnsworth et al. 2014). Despite the destructive nature of HLB in citriculture, neither an effective control strategy nor resistant varieties have been developed yet (Gottwald 2010). At present, citrus industry heavily depends on year-round chemical sprays to control the insect set and the tissue sample are indicated in the figure together with the number of CLas positives and the total number of samples. Asterisk indicates number of CLas positive/Total number of samples. The $x$ in the agarose gel indicates samples $(\mathrm{Ct}=\sim 36)$ for which the conventional PCR failed

vector (psyllid) population and additional nutrient application to maximize the yield when HLB is widespread, thus greatly increasing production costs (Farnsworth et al. 2014). However, this strategy has only limited effect on controlling HLB spread because there has been no early HLB detection method developed yet, which can be useful for the removal of HLB positive trees at pre-symptomatic stage.

Currently, routine HLB diagnosis is conducted by visual inspection of a tree canopy for typical HLB symptoms; realtime PCR using DNA extracted from symptomatic leaves is merely a confirmation of HLB in a symptomatic tree. Since HLB symptom development is a slow process taking a few months to 1 or more years, it is highly likely that any infected tree without visible HLB symptoms will not be selected for testing and thus will serve as an inoculum source for HLB (Lee et al. 2015). Our group previously reported that HLBcausing bacteria are relatively even distributed in the citrus root system compared to the aerial part of a tree infected with CLas (Kunta et al. 2014a; Louzada et al. 2016), suggesting that the root tissue can be an alternative source material for routine HLB diagnosis. The current study was initiated to examine the root tissue as an alternative source material for HLB diagnosis. However, due to the non-specific amplification of HLBaspr, a widely used real-time PCR primer-probe set for HLB diagnosis, with root DNA fraction (Kunta et al. 2014b; Louzada et al. 2016), the current study first focused 
on the development of a new primer-probe set, TXCChlb, based on CLas $16 \mathrm{~s}$ rDNA and then optimized the root DNA preparation for PCR by incorporating a step to remove PCR inhibitors present in the root DNA fraction. The development and evaluation of primer-probe set TXCChlb using DNA from leaves and fibrous roots collected from young citrus trees in Texas and Florida confirmed that HLB can be detected using real-time PCR with TXCChlb from roots before symptoms appear aboveground. This early detection will help provide more effective HLB control, especially where HLB disease is not yet widespread. In addition, the use of TXCChlb with real-time PCR has potential for detecting CLam from fibrous root tissue. In regions where CLam coexists with CLas, the cPCR confirmation step is also required to confirm the identity of HLB-causing bacteria.

Acknowledgements We greatly thank Jim Brockington (Citrus Center, Texas A\&M Univ.-Kingsville, Weslaco, TX) and Barry C. Kostyk (University of Florida-IFAS, Southwest Florida Research and Education Center, Immokalee, FL) for collecting and processing tissue samples. We also thank Jennifer Trevino at Wonderful Citrus in Edinburg, Texas for her help with tissue sampling and Yessica Cerino at the Citrus Center, Texas A\&M Univ.-Kingsville, for reviewing the manuscript. This work was supported by funds from USDA-APHIS PPQ, USDA MAC cooperative agreement \#15-8130-0489-CA.

\section{Compliance with Ethical Standards}

Ethical approval This article does not contain any studies with human participants or animals performed by any of the authors.

Conflicts of interest The authors declare that they have no conflict of interest.

Open Access This article is distributed under the terms of the Creative Commons Attribution 4.0 International License (http://creativeco mmons.org/licenses/by/4.0/), which permits use, duplication, adaptation, distribution and reproduction in any medium or format, as long as you give appropriate credit to the original author(s) and the source, provide a link to the Creative Commons license and indicate if changes were made.

\section{References}

Bové JM (2006) Huanglongbing: a destructive, newly-emerging, century-old disease of citrus. J Plant Pathol 88:7-37

Capoor SP, Rao DG, Viswanath SM (1967) Diaphorina citri Kuway., a vector of the greening disease of citrus in India. Ind J Agric Sci 37:572-576

da Graça JV, Korsten L (2004) Citrus Huanglongbing: review, present status and future strategies. In: Naqvi SAMH (ed) Diseases of fruits and vegetables, vol 1. Springer, Dordrecht, Netherlands, pp 229-245

Farnsworth D, Grogan KA, van Bruggen AHC, Moss CB (2014) The potential economic cost and response to greening in Florida citrus. Choice 29:1-6

Fujikawa T, Iwanami T (2012) Sensitive and robust detection of citrus greening (huanglongbing) bacterium "Candidatus Liberibacter asiaticus" by DNA amplification with new 16S rDNA-specific primers. Mol Cell Probes 26:194-197

Gottwald TR (2010) Current epidemiological understanding of citrus Huanglongbing. Annu Rev Phytopathol 48:119-139

Gottwald TR, Parnell S, Taylor E, Poole K, Hodge J, Ford A, Therrien L, Mayo S, Irey M (2008) Within-tree distribution of Candidatus Liberibacter asiaticus. In: Gottwald TR, Graham JH (eds) Proceedings of the 1st International Research Conference on Huanglongbing. Florida Citrus Mutual, Orlando, FL, USA, pp 310-313

Halbert SE (2005) The discovery of huanglongbing in Florida. Proceedings of the international citrus canker and huanglongbing research workshop, Orlando, FL, USA, H-3 (Abstract)

Jagoueix S, Bové JM, Garnier M (1994) The phloem-limited bacterium of greening disease of citrus is a member of the $\alpha$ subdivision of the Proteobacteria. Int J Syst Bacteriol 44:379-386

Jagoueix S, Bové JM, Garnier M (1996) PCR detection of the two 'Candidatus' liberobacter species associated with greening disease of citrus. Mol Cell Probes 10:43-50

Johnson EG, Wu J, Bright DB, Graham JH (2014) Association of 'Candidatus Liberibacter asiaticus' root infection, but not phloem plugging with root loss on huanglongbing-affected trees prior to appearance of foliar symptoms. Plant Pathol 63:290-298

Koressaar T, Remm M (2007) Enhancements and modifications of primer design program Primer3. Bioinformatics 23:1289-1291

Kunta M, da Graça JV, Malik N, Louzada ES, Sétamou M (2014a) Quantitative distribution of Candidatus Liberibacter asiaticus in the aerial parts of the Huanglongbing-infected citrus trees in Texas. HortScience 49:65-68

Kunta M, Viloria Z, del Rio HS, Louzada ES (2014b) Diverse DNA extraction methods and PCR primers for detection of Huanglongbing-associated bacteria from roots of 'Valencia' sweet orange on sour orange rootstock. Scientia Horticult 178:23-30

Lee JA, Halbert SE, Dawson WO, Robertson CJ, Keesling JE, Singer BH (2015) Asymptomatic spread of huanglongbing and implications for disease control. Proc Natl Acad Sci USA 112:7605-7610

Li W, Hartung JS, Levy L (2006) Quantitative real-time PCR for detection and identification of Candidatus Liberibacter species associated with citrus huanglongbing. J Microbiol Methods 66:104-115

Louzada ES, Vazquez OE, Braswell WE, Yanev G, Devanaboina M, Kunta M (2016) Distribution of 'Candidatus Liberibacter asiaticus' above and below ground in Texas citrus. Phytopathology 106:702-709

McClean APD, Oberholzer PCJ (1965) Citrus psylla, a vector of the greening disease of sweet orange. S Afr J Agric Sci 8:297-298

Monzo C, Stansly PA (2017) Economic injury levels for Asian citrus psyllid control in process oranges from mature trees with high incidence of huanglongbing. PLoS One 12:e0175333

Morgan JK, Zhou L, Li W, Shatters RG, Keremane M, Duan YP (2012) Improved real-time PCR detection of 'Candidatus Liberibacter asiaticus' from citrus and psyllid hosts by targeting the intragenic tandem-repeats of its prophage genes. Mol Cell Probes 26:90-98

Planet P, Jagoueix S, Bové JM, Garnier M (1995) Detection and characterization of the African citrus greening liberobacter by amplification, cloning, and sequencing of the rplKAJL-rpoBC operon. Curr Microbiol 30:137-141

Shen W, Halbert SE, Dickstein E, Manjunath KL, Shimwela MM, van Bruggen AHC (2013) Occurrence and in-grove distribution of citrus huanglongbing in north central Florida. J Plant Pathol 95:361-371

Teixeira DC, Ayres AJ, Danet JL, Saillard ES, Bové JM (2005) First report of a huanglongbing-like disease of citrus in Sao Paulo State, Brazil, and association of a new Liberibacter species, "Candidatus Liberibacter americanus", with the disease. Plant Dis 89:107 
Wang N, Trivedi P (2013) Citrus huanglongbing: a newly relevant disease presents unprecedented challenges. Phytopathology 103:652-665

Wang Z, Yin Y, Hu H, Yuan Q, Peng G, Xia Y (2006) Development and application of molecular-based diagnosis for 'Candidatus Liberibacter asiaticus', the causal pathogen of citrus huanglongbing. Plant Pathol 55:630-638

Yarza P, Ludvig W, Euzéby J, Amann R, Schleifer KH, Glöckner FO, Rosselló-Móra R (2010) Update of the all-species living tree project based on $16 \mathrm{~S}$ and 23S rRNA sequence analyses. Sys Appl Microbiol 33:291-299

Zheng Z, Xu M, Bao M, Wu F, Chen J, Deng X (2016) Unusual five copies and dual forms of $n r d B$ in "Candidatus Liberibacter asiaticus": Biological implications and PCR detection application. Sci Rep 6:39020 